Journal of Teacher Education for Sustainability, vol. 21, no. 2, pp. 38-55, 2019

\title{
Analytical Study Based on Perspectives of Teacher Educators in India with Respect to Education for Sustainable Development
}

\author{
Manisha Jetly and Nandita Singh \\ Panjab University, Chandigarh, India
}

\begin{abstract}
Education for sustainable development (ESD) has been accepted worldwide as one of the most powerful paradigms of thinking, which has a potential for changing the ongoing course of unsustainable development in order to save the fate of life on Mother Earth. As we prepare ourselves to achieve the 17 sustainable development goals (SDGs) of United Nations 2030 Agenda, it is crucial to analyze and reflect on the initiatives taken, which aim at sensitizing the stakeholders of education with the holistic concept of ESD, especially when it has been reported in the literature that countries of the Asia Pacific region have been slow in formally embracing the concept of ESD in their education system. With this contextual background, the present research paper aimed at understanding the prevailing perception of ESD amongst the teacher educators of India. A qualitative deductive content analysis methodology was adopted for an in-depth analysis of the subjective responses of teacher educators, teaching graduate and post-graduate level courses of teacher education programs of India's Chandigarh region. A codebook was developed on the basis of UNESCO's Teaching and Learning for a Sustainable Future (TLSF) program for the analysis. The findings of the research identified how and to what extent the indicators of ESD were addressed through broader categories of knowledge, skills and values. The research joins larger conversation of reorienting the teacher education programs particularly through the lens of cultural sustainability to achieve a sustainable future.
\end{abstract}

Key words: teacher education, curriculum framework, content analysis, education for sustainable development, cultural sustainability

\section{Introduction}

The concern towards man's materialistic attitude that might question the existence of life on Mother Earth was envisioned many decades ago by the Father of the Nation, India, Mahatma Gandhi. The ongoing journey of unsustainable development validates this concern: Earth has enough resources for everybody's needs but not for anybody's greed (Mahatma Gandhi). 
Soon after industrialization there was desperation of hurrying up the so-called development process through the indicator of economic growth, which resulted into reckless exploitation of natural resources (Sathapathy, 2010). This has resulted in massive assault on the balance of the nature's systems, the repercussions of which are evident in the form of climate change and increasing unrest in the society.

Further globalization, which according to its critics aimed at cultural penetration and economic dominance, exploited physically and psychologically human and nonhuman resources of the developing countries, which led to the homogenization of mankind. As a result, these days people look alike, eat alike, dress alike, even think alike, hence, speeding together on the unsustainable path of the modern development. There are a plethora of statements from the past, in which the great leaders and scholars warned humanity regarding this so-called materialistic modern development. Rachel Carson's remark in 1963 that, "Man's attitude toward nature is today critically important simply because we have now acquired a fateful power to alter and destroy nature. But man is part of nature, and his war against nature is inevitably a war against himself", holds true and relevant that highlights the self-destructive nature of the modern development into which we all have indulged, just to satisfy our greed for more and more materialistic possessions, as in today's modern society individuals with maximum materialistic possession are considered most successful, powerful and important, whereas individuals who possess the wealth in the form of wisdom, knowledge, contentment and happiness are rarely noticed or acknowledged.

It is high time that each one of us takes a moral responsibility of reversing such kind of hollow meaning of development and success of the modern societies, as these dispositions are the fundamental cause of the ongoing humanitarian crisis, which is questioning the existence of our own children and grandchildren. To motivate an individual to take upon such kind of moral responsibility and to find the solutions and act accordingly, thinking of an individual has to be changed, and to change the thinking process, we need to change our education system. A critical review of literature acknowledged the significance of education and the pivotal role of teachers for achieving a sustainable future (Bürgener \& Barth, 2018; Hopkins \& McKeown, 2002; McKeown, 2002; Nolet, 2009; United Nations Educational, Scientific and Cultural Organization (UNESCO) 2005, 2006, 2010, 2018). Moreover, several methodologies and initiatives have been proposed for inclusion of ESD in formal education. However, at the same time it has been reported that not much success has been achieved. As stated by Mulà et al. (2016), schools engaged in sustainability agenda in the Asia Pacific region are still in minority. A very relevant recent analytical study by Hallinger and Chatpinyakoop (2019) has highlighted the dearth of research studies in the developing societies in the context of ESD, in which on the basis of bibliometric review of 1459 Scopus-indexed documents for the period of 1998-2018, related to higher education and ESD, it has been reported that only $16 \%$ of the studies have been authored by the scholars of developing societies. It has also been recognized that it is a concerning trend as the repercussions of unsustainable development will be felt mostly by the developing societies. In this context, it has been stated that "Resource scarcity in developing societies frequently leads to a survivalist mind-set that leads policymakers to borrow against the future. In addition, when the effects of unsustainable development do arise in developing societies, fewer resources are available to buffer the impact". The findings of the above-mentioned 
studies in relation to the Asia-Pacific region and developing countries raise the questions on the impact and effectiveness of the number of initiatives, which the world community has undertaken in recent decades in the direction of sustainable development.

\section{Moving towards Deeper Engagement with Education for Sustainable Development}

As the world community prepares itself for the ambitious sustainable development goals (SDGs) for achieving Agenda 2030, the main questions are: Has our efforts in the past decades been successful in making a bigger societal impact? Have rich and educated people who understand and propagate the concept of sustainability adapted a sustainable lifestyle? Has consumerism decreased? Have we been able to reverse the climate change? These are some pertinent questions which remain unanswered even after decades of endless debates, discussions, seminars and conferences on sustainable development worldwide.

A critical review of literature suggested that there was a worldwide acceptance of integrating ESD at all levels of education irrespective of the discipline (Altomonte, Rutherford, \& Wilson, 2012; Badjanova, Iliško, \& Drelinga, 2014; Burmeister \& Eilks, 2012; Chhokar, 2010; Darwish, Agnello, \& Burgess, 2010; Dawe, Gant, \& Taylor, 2003; Hägglund \& Samuelsson, 2009; Robinson, 2004; Tilbury, 2007). Since all levels of education system have a symbiotic relationship in which teachers are like bridges, to bring sustainability into our classrooms at any level, it is crucial to address sustainable development first in teacher education programs.

In this context, various attempts have been made and proposed to effectively integrate issues of sustainability in teacher education programs, for example, an interdisciplinary approach, embedded sustainability curriculum, pedagogies like collaborative learning, investigatory methods, real-world problem solving, e-learning strategies, effective instruction strategies, action research projects, transdisciplinary research (Bell, 2016; Evans, Stevenson, Lasen, Ferreira, \& Davis, 2017; Howard, 2015; Salite, 2008; Tomas, Girgenti, \& Jackson, 2017; Bürgener \& Barth, 2018). In addition, various studies have centered around the idea of internalizing ESD through self-initiative and self-reflection (Barth, Godemann, Rieckmann, \& Stoltenberg, 2007; Davis, Edmister, Sullivan, \& West, 2003; Summers \& Kruger, 2003) along with increasing the sustainability consciousness (Berglund, Gericke, \& Chang Rundgren, 2014).

Despite many proposals and initiatives, serious questions arise: Are teachers themselves interested, willing or committed towards ESD? Have they been sensitized to such an extent that they can become role models of sustainability?

It is important to understand that at this juncture the soft, superficial and fragmented treatment of ESD, by transferring knowledge in a sequential or linear manner and treating each SDG separately, will not be helpful in bringing about the change, which we as a world community are aiming at in the form of Agenda 2030. A deep engagement with sustainability is essential, which can sensitize deeper layers of consciousness so that sustainability can be practised and lived, rather than just preaching about it.

Deeper layers of consciousness can be only touched upon when it is realized that the repercussions of unsustainable development will be directly affecting us at a personal level. Furthering this sentiment, Ikerd (2014) proposed the concept of deep sustainability 
which "addressed the ethical, philosophical, and spiritual roots of human well-being that must sustain the ecological, social, and economic integrity of human relationships with each other and with nature." The deep sustainability idea was also reflected by the UNESCO's Teaching and Learning for a Sustainable Future (TLSF) program (UNESCO, 2010), which discussed the concept of ethic of sustainability through social justice values and conservation values, which should be nurtured in the teachers so that their actions and everyday choices would reflect sustainability, hence inspiring their students to follow the same.

For the successful and effective integration of ESD in the formal education system, a compelling suggestion was made by Bussey (2008), in which he developed upon the idea that teachers have to become role models of sustainability, in which they would have to live the idea of sustainability rather than preaching it. According to Bussey (2008), "Sustainable education is not a didactic process but an embodied and relational engagement with life; and to teach sustainability we have to live it." He defined sustainable educators as, "those who care, transgress, inspire, love, enlighten, question, challenge, reconfigure, reinscribe, by embodying their passion for learning, for living and for humanity and the planet."

The above idea of a sustainable educator is the real hope for attainment of a sustainable future. However, for nurturing such kind of transformational educators, the motivation and commitment have to come from within, which is possible if we address the concept of ESD in the context of personal belief system of every individual, which can be either culturally or religiously acquired. It is believed that such kind of individualistic and unique engagement with sustainability based on one's belief system may have the power to sensitize deeper layers of consciousness, as instinctively it will be felt familiar, natural and right to every individual. This kind of approach directly associates with the essence of cultural sustainability, in which the ingrained, unique sustainability practices of various cultures motivate intrinsically an individual to follow a path of a sustainable future.

\section{India and Education for Sustainable Development}

India, a country with approximately 1.3 billion people, is geographically, culturally and religiously diverse in nature and celebrates ideas of "unity without uniformity" and "diversity without fragmentation". India has a history of low carbon footprint which has been possible due to a sustainable lifestyle governed by deeply ingrained sustainable practices of the diverse cultures of India (Ministry of Environment, Forest and Climate Change, n.d.).

However, the globalization led to increased consumerism behavior in India, as it brought with it various multinational companies which noticeably increased the purchasing power of the common man of India. It can be clearly experienced that the Indian households, which once encouraged the three R's of sustainability (reduce, recycle and reuse) through the range of everyday practices, are currently in a decline. For example, it was considered very normal amongst children to wear the clothes worn by elder children; books, toys were passed on within the family. Such a behavior is rare these days.

The ancient Indian education system has always been value oriented, in which a teacher has been regarded equivalent to a Guru, which means the supreme God, who 
creates, sustains knowledge and destroys the weeds of ignorance for our betterment. But what about the Gurus of the modern India? Are they empowered and enlightened enough to guide the mankind towards the sustainable development?

Studies in literature acknowledged that the launch of Decade of Education for Sustainable Development (DESD) galvanized ESD moment in India (Chokkar, 2010). However, it did not make any major impact on effectively integrating ESD in formal curricula. The review of literature suggested that efforts taken were mostly environmentally dominated, focusing more towards greening of schools and campuses, and missing upon the social, economic and cultural dimensions of ESD (Iyengar \& Bajaj, 2011). Unfortunately, the scenario was focused on teacher education in India. The preservice and in-service teacher education curricula have very little exposure to sustainability issues, as discipline oriented teaching is encouraged. Lesson plans are still made keeping in focus the discipline, hence failing in addressing the real life problems, which are not limited by the tight disciplinary boundaries.

A study reported that there were only a handful of universities in India, which addressed sustainability issues at graduate and post-graduate levels of teacher education courses (Gafoor \& Mumthas, 2011). Moreover, as reported by Mishra (2002) the understanding of sustainability was mostly environmental in nature amongst pre-service and in-service teachers.

The review of literature suggested that there was dearth of research studies in the context of ESD and teacher education. Therefore, with this contextual background, the present research was undertaken to analyze the perceptions of teacher educators of Chandigarh region of India towards ESD. According to authors' knowledge, the study is the first of its kind in this region of the country. The objective of the study was to analyze how and to what extent teacher educators, the ones who were responsible for educating teachers, perceived the concept of ESD.

\section{Methodology}

Twenty teacher educators from the teacher educational institutes of Chandigarh, located in the northwest region of India, participated voluntarily in a survey where they were asked to give their perception towards the meaning of the ESD through an open ended question: "What do you think Education for Sustainable Development might mean?". This gave an opportunity to the teacher educators to respond freely about their perception towards ESD.

Thereafter, a qualitative deductive content analysis methodology was adopted for the analysis of the twenty subjective responses for which a codebook was developed with categories, sub-categories, indicators, and guidelines for coding. UNESCO's TLSF (UNESCO, 2010) was the guiding program followed for the development of the codebook. The program has its mention in various policy documents and research papers (Dyment \& Hill, 2015; Steele, 2010; Zeegers \& Clark, 2014). Recently, its relevance has been validated as a significant resource material for integrating ESD in teacher education during UNESCO (2018) Conference on Integrating Education for Sustainable Development (ESD) in Teacher Education in South-East Asia.

The outline of coding framework developed for the present study is presented in Table 1. 


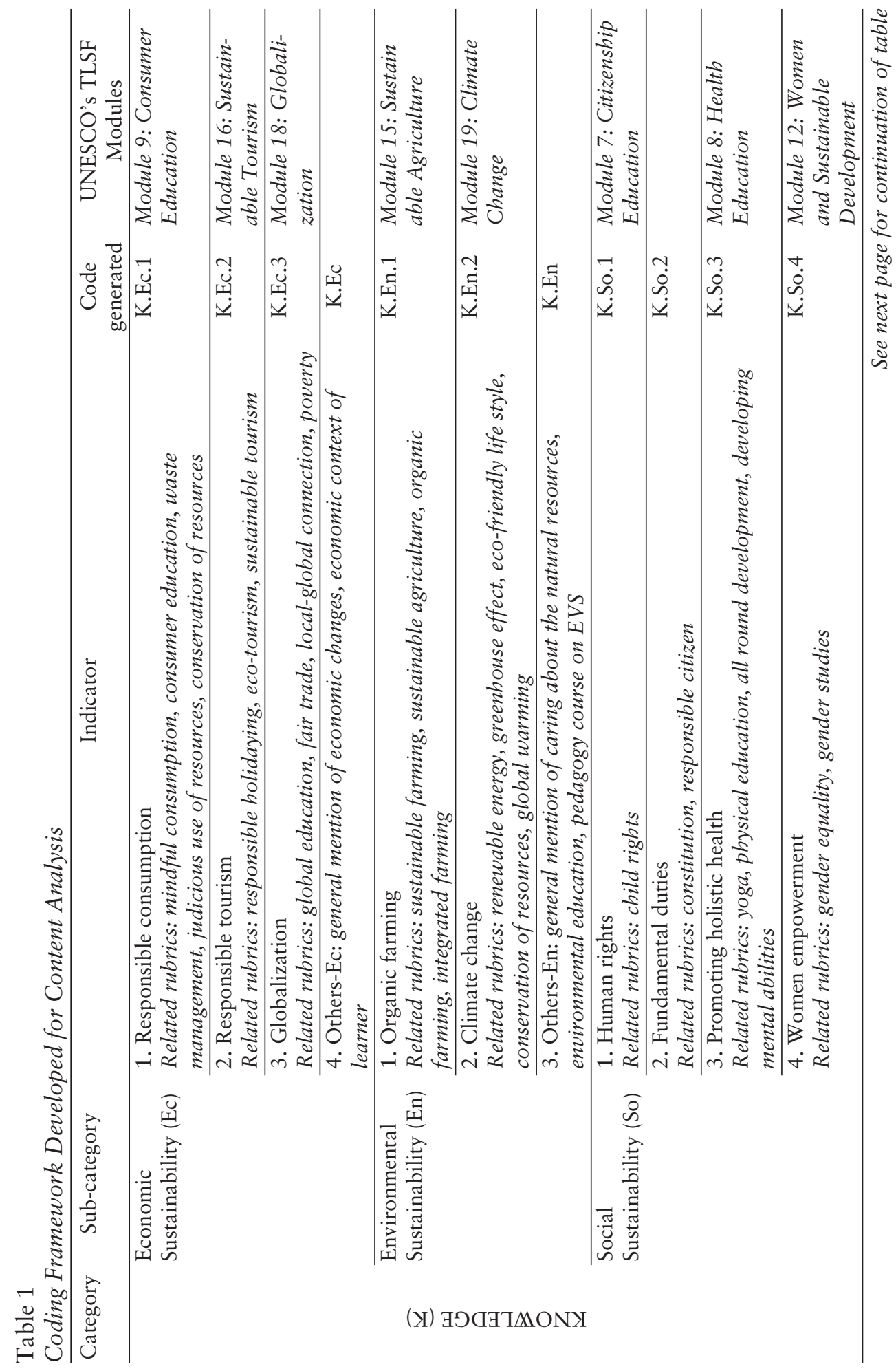




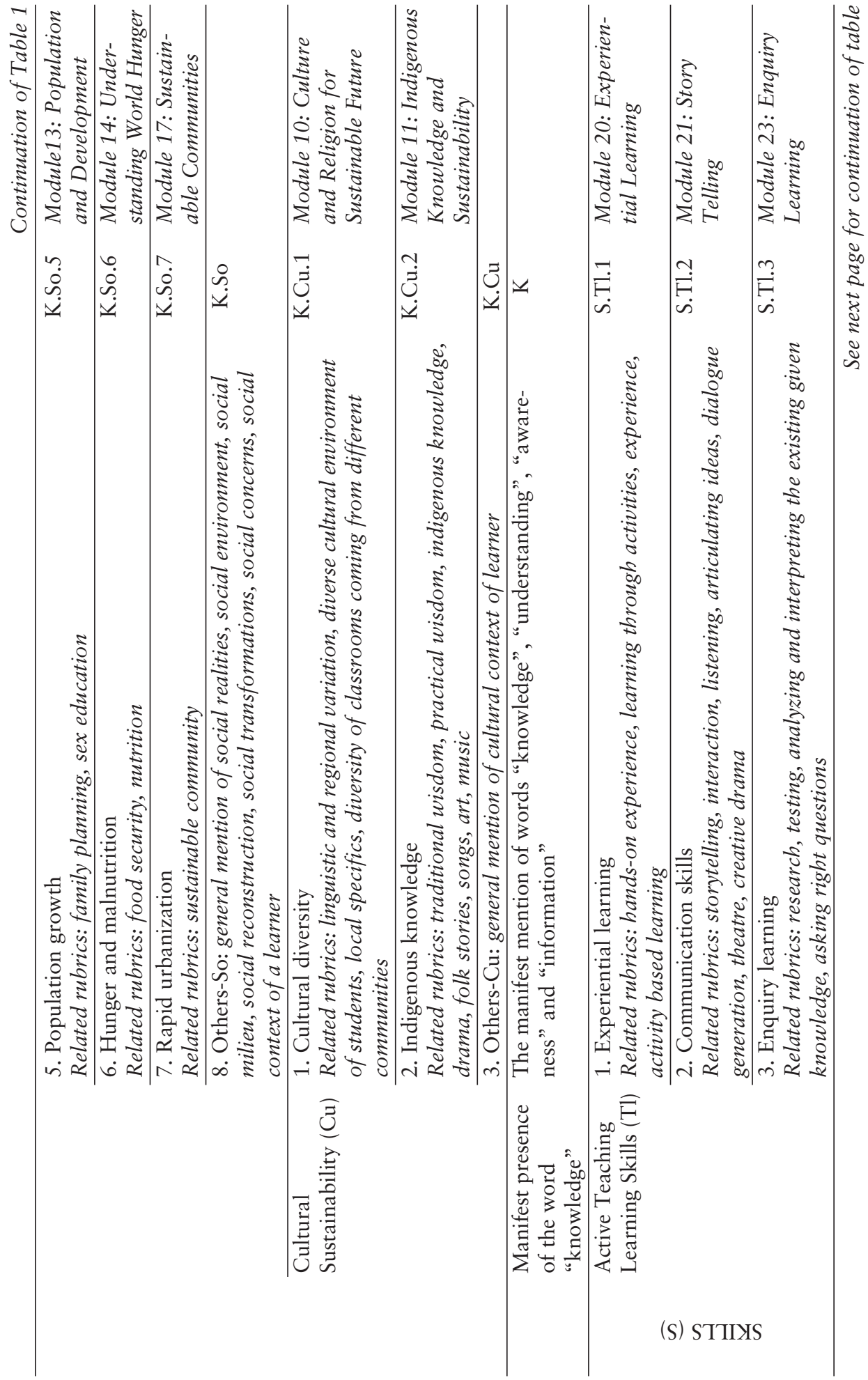




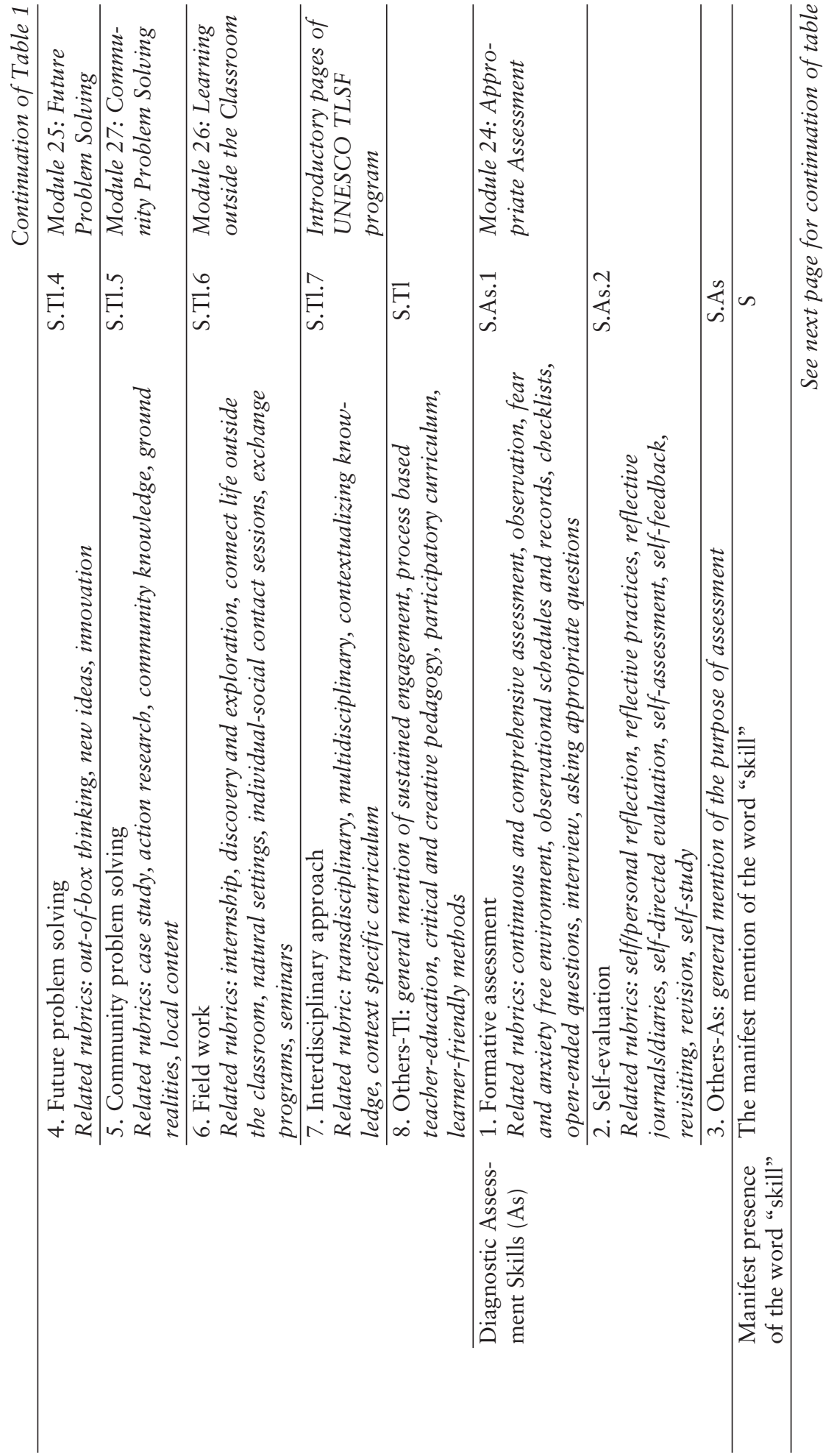




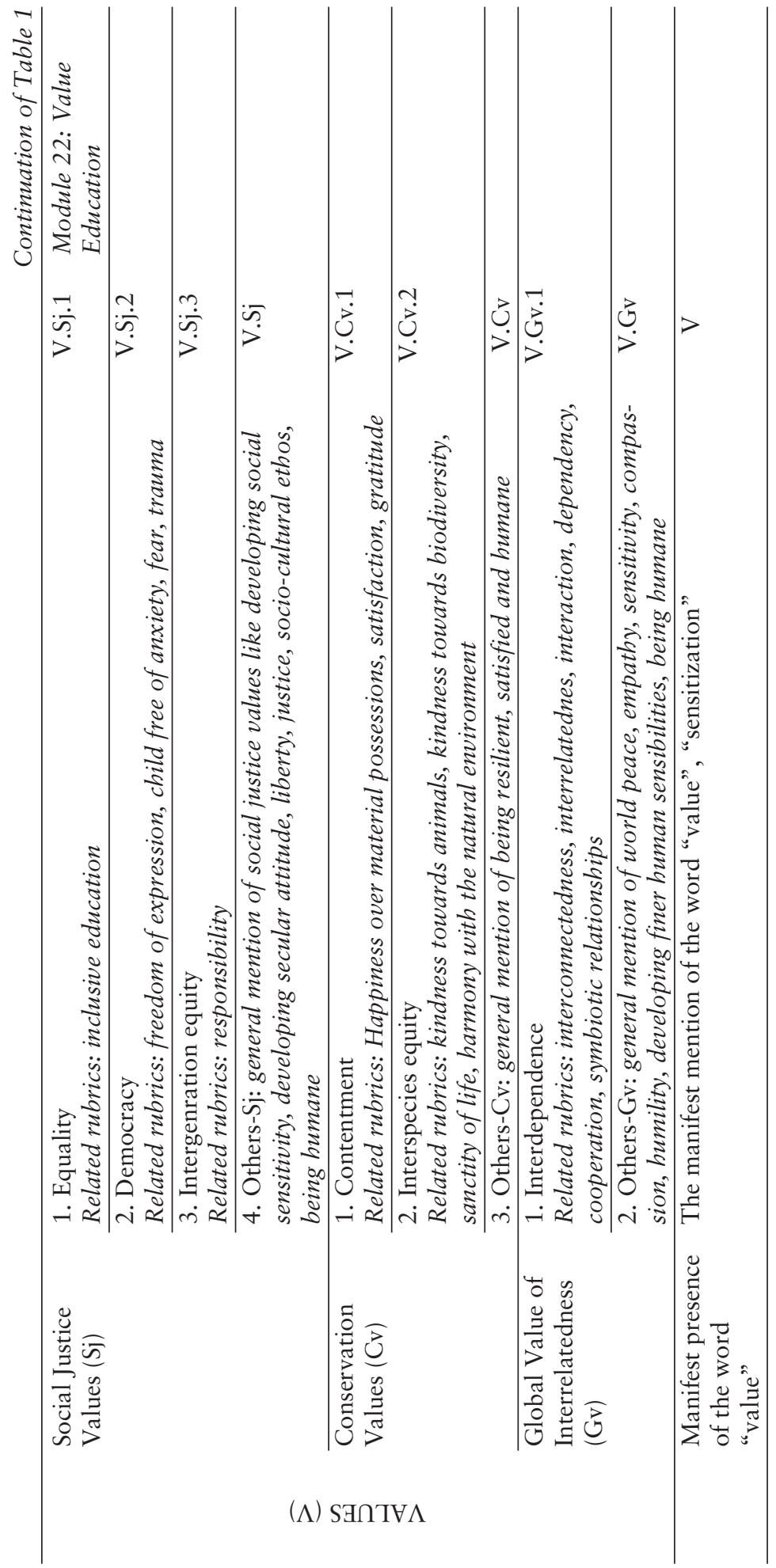




\section{Discussion of the Findings}

The total codes generated were analyzed for the three categories of ESD: knowledge, skills, values, in which maximum generated codes belonged to knowledge category $(46 \%)$ followed by value category $(39 \%)$ and skill category $(15 \%)$.

The discussion of results for each category is provided below.

\section{Knowledge Category}

Knowledge acts as a propeller to direct our actions, our values on the basis of which our pursuit to a sustainable future can be achieved. Appropriate awareness, understanding and knowledge of the issues related to sustainable development can act as a foundation for a sustainable future.

- The analysis of teacher educators' subjective responses towards ESD for the knowledge category as given in Table 2 suggested that respondents associated environmental sustainability significantly (39\%) with the meaning of ESD. The respondents mentioned climate change; pollution of land, water, air; mitigating carbon dioxide concentration level; using less CFCs; preservation of natural resources; resilience and adaptation in ecosystem; encouraging use of renewable resources; maintaining a balance in the utilization of natural resources along with judicious use of resources, which highlighted the indicators of environmental sustainability.

However, it was observed that most of respondents used scientific terminology in the context of the environmental sustainability limiting the perception to scientific facts and terms.

- The economic sustainability issues were moderately addressed (26\%), in which the indicator responsible consumption was discussed the most in the context of using and preserving natural resources. Further the resilience and adaptation of the economy were also mentioned. The manifest presence of the word "knowledge" $(19 \%)$ and its synonyms such as awareness, information asserted the role of knowledge in the context of teacher educators' perception towards the meaning of ESD.

- The social sustainability was recognized comparatively less $(13 \%)$ by the respondents in which human rights, fundamental duties and resilience, adaptation in politics highlighted the indicators of social sustainability. However, it should be noted that certain critical issues such as promoting holistic health, women empowerment, population growth, hunger and malnutrition, as well as rapid urbanization remained unaddressed.

- It is worrisome that in a country with rich cultural heritage the indicators of cultural sustainability were least $(3 \%)$ and weakly addressed by the respondents.

Overall, a similar pattern was observed as reported by Khalil, Ramzy, and Mostafa (2013) where students' perception towards ESD was related to the environment aspect followed by the economic aspect and the social aspect. In addition, studies by Azapagic, Perdan, and Shallcross (2005) and Cebrián and Junyent (2015) also acknowledged the same trend. 
Table 2

Frequency Distribution of Codes Generated for Knowledge Category

\begin{tabular}{llc}
\hline Code & \multicolumn{1}{c}{ Explanation: Category. Sub-category. Indicator } & $\begin{array}{c}\text { Occurrence of code in the } \\
\text { knowledge category }(\%)\end{array}$ \\
\hline K.Ec.1 & $\begin{array}{l}\text { Knowledge. Economic sustainability. Responsible con- } \\
\text { sumption }\end{array}$ & $22.6 \%$ \\
\hline K.Ec.2 & Knowledge. Economic sustainability. Responsible tourism & $0.0 \%$ \\
\hline K.Ec.3 & Knowledge. Economic sustainability. Globalization & $0.0 \%$ \\
\hline K.Ec & Knowledge. Economic sustainability. Others-Ec & $3.2 \%$ \\
\hline & Total \% of codes generated for economic sustainability & $\approx 26.0 \%$ \\
\hline K.En.1 & Knowledge. Environmental sustainability. Organic farming & $3.2 \%$ \\
\hline K.En.2 & Knowledge. Environmental sustainability. Climate change & $6.5 \%$ \\
\hline K.En & Knowledge. Environmental sustainability. Others-En & $29.0 \%$ \\
\hline & Total \% of codes generated for environmental sustainability & $\approx 39.0 \%$ \\
\hline K.So.1 & Knowledge. Social sustainability. Human rights & $6.5 \%$ \\
\hline K.So.2 & Knowledge. Social sustainability. Fundamental duties & $3.2 \%$ \\
\hline K.So.3 & Knowledge. Social sustainability. Promoting holistic health & $0.0 \%$ \\
\hline K.So.4 & Knowledge. Social sustainability. Women empowerment & $0.0 \%$ \\
\hline K.So.5 & Knowledge. Social sustainability. Population growth & $0.0 \%$ \\
\hline K.So.6 & Knowledge. Social sustainability. Hunger and malnutrition & $0.0 \%$ \\
\hline K.So.7 & Knowledge. Social sustainability. Rapid urbanization & $0.0 \%$ \\
\hline K.So & Knowledge. Social sustainability. Others-So & $3.2 \%$ \\
\hline & Total \% of codes generated for social sustainability & $\approx 13.0 \%$ \\
\hline K.Cu.1 & Knowledge. Cultural sustainability. Cultural diversity & $3.2 \%$ \\
\hline K.Cu.2 & Knowledge. Cultural sustainability. Indigenous knowledge & $0.0 \%$ \\
\hline K.Cu & Knowledge. Cultural sustainability. Others-Cu & $0.0 \%$ \\
\hline & Total \% of codes generated for cultural sustainability & $\approx 3.0 \%$ \\
\hline k & Manifest presence of the word “knowledge” & $\approx 19.0 \%$ \\
\hline & &
\end{tabular}

\section{Skill Category}

Meaningful and engaging skills are important for effective application of knowledge.

- For the skill category it can be inferred from Table 3 that maximum codes generated addressed the manifest presence of the word "skill” (80\%), which implied that teacher educators significantly associated the general importance of overall competences, abilities with the meaning of ESD. Previous studies by Hägglund and Samuelsson (2009), Manni, Ottander, Sporre, and Parchmann (2013) also emphasized the importance of pedagogical skills in the context of ESD.

- The respondents rarely mentioned specific skills; however, slight focus was given to the field work and life related experiences, which contributed to active teaching-learning skills $(20 \%)$.

- However, there was no response, which highlighted the diagnostic assessment skills. 
Table 3

Frequency Distribution of Codes Generated for Skill Category

\begin{tabular}{clc}
\hline Code & \multicolumn{1}{c}{ Explanation: Category. Sub-category. Indicator } & $\begin{array}{c}\text { Occurrence of code in } \\
\text { the skill category }(\%)\end{array}$ \\
\hline S.Tl.1 & Skill. Teaching learning. Experiential learning & $0.0 \%$ \\
\hline S.Tl.2 & Skill. Teaching learning. Communication skills & $0.0 \%$ \\
\hline S.Tl.3 & Skill. Teaching learning. Enquiry learning & $0.0 \%$ \\
\hline S.T1.4 & Skill. Teaching learning. Future problem solving & $0.0 \%$ \\
\hline S.T1.5 & Skill. Teaching learning. Community problem solving & $0.0 \%$ \\
\hline S.Tl.6 & Skill. Teaching learning. Field work & $10.0 \%$ \\
\hline S.Tl.7 & Skill. Teaching learning. Interdisciplinary approach & $0.0 \%$ \\
\hline S.T1 & Skill. Teaching learning. Others-Tl & $10.0 \%$ \\
\hline & Total \% of codes generated for active teaching learning skills & $20.0 \%$ \\
\hline S.As.1 & Skill. Assessment. Formative assessment & $0.0 \%$ \\
\hline S.As.2 & Skill. Assessment. Self-evaluation & $0.0 \%$ \\
\hline S.As & Skill. Assessment. Others-As & $0.0 \%$ \\
\hline & Total $\%$ of codes generated for diagnostic assessment skills & $0.0 \%$ \\
\hline s & Manifest presence of the word "skill” & $80.0 \%$ \\
\hline
\end{tabular}

\section{Value Category}

Skill and knowledge without values can lead to disastrous results and the present course of materialistic modern development is the result of the same. On the basis of value system, an individual makes choices, and at a larger scale these choices can either sustain or curtail the mankind. A detailed overview of the frequency of each code out of total codes generated for the teacher educators' response for the value category is presented in Table 4.

Table 4

Frequency Distribution of Codes Generated for Value Category

Code Explanation: Category. Sub-category. Indicator

Occurrence of code in the value category $(\%)$

\begin{tabular}{clc}
\hline V.Sj.1 & Value. Social-justice values. Equality & $3.8 \%$ \\
\hline V.Sj.2 & Value. Social-justice values. Democracy & $0.0 \%$ \\
\hline V.Sj.3 & Value. Social-justice values. Inter-generation equity & $15.4 \%$ \\
\hline V.Sj & Value. Social-justice values. Others-Sj & $0.0 \%$ \\
\hline & Total \% of codes generated for social-justice values & $\approx 19.0 \%$ \\
\hline V.Cv.1 & Value. Conservation values. Contentment & $11.5 \%$ \\
\hline V.Cv.2 & Value. Conservation values. Inter-species equity & $11.5 \%$ \\
\hline V.Cv & Values. Conservation values. Others-Cv & $0.0 \%$ \\
\hline & Total \% of codes generated for conservation values & $23.0 \%$ \\
\hline V.Gv.1 & Value. Global value of interrelatedness. Interdependence & $11.5 \%$ \\
\hline V.Gv & Value. Global value of interrelatedness. Other-Gv & $19.2 \%$ \\
\hline & Total \% of codes generated for global value of interre- & $\approx 31.0 \%$ \\
\hline & latedness & $27.0 \%$ \\
\hline & Manifest presence of the word “value”
\end{tabular}


- It can be inferred that maximum codes generated addressed global value of interrelatedness (31\%), in which the respondents focused on harmonious interaction among humans, animals and natural resources. The respondents frequently associated the world with family, save and serve humanity, help mankind, save humanity from destruction, make world safer, healthier and more livable place for us and the future generation.

- The manifest presence of the word "values" $(27 \%)$ highlighted respondents' association of the meaning of ESD directly with the term "value".

- There was a moderate presence of conservation values (23\%), which was highlighted through interesting responses for the indicator contentment. For example, the following responses were provided: "learning to live rather than learning to earn; controlling one's greed; happy human beings".

- Though the social justice values were least addressed (19\%) by the respondents, they brought forth a crucial indicator of inter-species equity through the following responses: "future generations are left with enough to lead a life with all the fruits of nature available to them as we are enjoying; leave to our next generation a better environment and natural resource base than what we inherited from our parents; creating better conditions for future; permitting social, economic and other needs for present and future generation; safer place for us and future generation".

The overall analysis of the findings of the subjective responses of the teacher educators suggested that they were familiar to a certain extent with the meaning of ESD. Moreover, general assertiveness appeared amongst the stakeholders towards ESD, which was in consonance with the studies by Anyolo, Kärkkäinen, and Keinonen (2018) and Kagawa (2007).

Further, an interesting finding that emerged was the emphasis on the knowledge category followed by the value and skill category. This pattern suggested that the respondents associated the meaning of ESD with knowledge, awareness, information and understanding towards the sustainability issues, in which values played a crucial role. Less focus towards the skill category suggested that actions and skills were not much associated with the meaning of ESD. It seems the meaning of ESD as perceived by the teacher educators was more theoretical and idealistic in nature rather than being practical and action oriented.

The findings of the present study highlight that the formal concept of ESD is still at a nascent stage especially in the teacher education programs of India. There is an underrepresentation of the issues of social, economic and cultural sustainability. Moreover, no emphasis is placed on the assessment practices in the context of ESD. However, at the same time it should be noted that the teacher educators associate values explicitly and elaborately with the meaning of ESD, which acknowledges the deeply ingrained sustainability values of the Indian culture.

\section{Conclusion}

India is a land of diversity, where after few kilometers the language, the food habits and the dressing style change. The Indian culture particularly has always motivated individuals to look beyond the materialistic aspects of life and aim for liberation; the 
Mukti, based on the actions; the Karmas, one performs. Reflecting this sentiment, ESD is seen as a ray of hope, which has the power to shudder the unsustainability forces and remind everyone that educational goals should not just aim for catering the immediate market needs but must sensitize stakeholders to make conscious choices for the inner peace, happiness, satisfaction and the prosperity of mankind for today and always.

The teacher educators have the power for initiating and facilitating the ripple effect of any new idea in an education system. However, we often overlook their far-reaching role and keep our focus only on teachers and students. The present research joins broader conversation of reorienting our present education system through ESD empowered teacher educators for accelerating the actions for vision of United Nations Agenda 2030. These transformational educators should have sustainability conditioned deeper layers of consciousness so that their teaching, their choices should be able to reflect the essence of sustainability, hence further motivating the student teachers towards sustainability.

The teacher educators in the present study significantly associate the meaning of ESD with the value of interrelatedness, which resonates with the essence of the Indian philosophy of "Vasudhaiva kutumbhakam" that means "the whole Earth is one family", hence fostering the essence of wholeness, harmony and responsibility towards each other, which are the founding values based on which sustainable development can blossom.

The culturally rich sustainable values of the Indian culture that are innately acquired by its native people through Sanskara; the genetic learning, make the Indians prepared and equipped to lead the humankind on the path of a sustainable future. However, with time such ideals grew dim under the dazzling effect of economically driven globalization. Deeper sensitization of the layer consciousness through ESD can help revitalize the Sanskars of Santosh (contentment) and Aparigraha (virtue of being non-attached to materialistic possessions, non-possessiveness/non-greediness), which are vital for saving the fate of humankind on Mother Earth. It is suggested that an ESD oriented teacher education curriculum framework formulated on the basis of indigenous knowledge, cultural wisdom will have the power of stimulating a chain reaction of sustainable development.

The cultural sustainability has a potential to provide both conceptual and practical tools for ESD. There are two aspects of cultural sustainability which makes it a significant driver for achieving sustainable development. The first one is the variety of sustainability friendly practices which every culture has been offering since ages for its sustenance. Moreover, recognition and respect for the diversity of cultures also create the conditions for mutual understanding, dialogue and peace. The ingrained religious beliefs of culture, local knowledge and practices can provide a valuable insight and act as an innovative tool for tackling the challenge of unsustainable pattern of development. The curriculum at all levels of education should introduce the expression of traditional knowledge in form of stories, epics, legends, folklore, rituals, songs, and laws, focusing on sustainability friendly traditions. The introduction of courses such as culture, religion and sustainable living, spreading awareness regarding our nature friendly traditions can help enrich our insight for a sustainable future (Briggs, 2005; Şuşnea, Vasiliu, \& Spiridon, 2014).

The second important aspect is the feeling of belongingness cultivated by culture sustainability, which leads to self-reflection and intrinsic motivation to make right choices for the betterment of those, to whom we can relate. This can initiate a chain reaction of value shift from being self-centered to community-centered, society-centered, nationcentered and, hence, spreading the essence of humanitarian attitude globally. 
Looking back to move ahead is the mantra that needs to be followed. Therefore, for achieving a vibrant and beautiful sustainable future it is time to rediscover, reconnect and reflect the already ingrained sustainability gems of our cultures.

\section{References}

Altomonte, S., Rutherford, P., \& Wilson, R. (2012). Mapping the way forward: Education for sustainability in architecture and urban design. Corporate Social Responsibility and Environmental Management, 21(3), 143-154. doi: 10.1002/ csr.1311

Anyolo, E. O., Kärkkäinen, S., \& Keinonen, T. (2018). Implementing education for sustainable development in Namibia: School teachers' perceptions and teaching practices. Journal of Teacher Education for Sustainability, 20(1), 64-81. doi: 10.2478/jtes-2018-0004

Azapagic, A., Perdan, S., \& Shallcross, D. (2005). How much do engineering students know about sustainable development? The findings of an international survey and possible implications for the engineering curriculum. European Journal of Engineering Education, 30(1), 1-19. doi: 10.1080/03043790512331313804

Badjanova, J., Iliško, Dz., \& Drelinga, E. (2014). Holistic approach in reorienting teacher education towards the aim of sustainable education: The case study from the regional University in Latvia. Procedia - Social and Behavioral Sciences, 116, 2931-2935. doi: 10.1016/j.sbspro.2014.01.682

Barth, M., Godemann, J., Rieckmann, M., \& Stoltenberg, U. (2007). Developing key competencies for sustainable development in higher education. International Journal of Sustainability in Higher Education, 8(4), 416-430. doi: 10.1108/ 14676370710 823582

Bell, D. V. (2016). Twenty-first century education: Transformative education for sustainability and responsible citizenship. Journal of Teacher Education for Sustainability, 18(1), 48-56. doi: 10.1515/jtes-2016-0004

Berglund, T., Gericke, N., \& Chang Rundgren, S. (2014). The implementation of education for sustainable development in Sweden: Investigating the sustainability consciousness among upper secondary students. Research in Science \& Technological Education, 32(3), 318-339. doi: 10.1080/02635143. 2014.944493

Briggs, J. (2005) The use of indigenous knowledge in development: Problems and challenges. Progress in Development Studies, 5, (version 2), 99-114. Retrieved from http://eprints.gla.ac.uk/1094/1/JBriggs_eprint1094.pdf

Bürgener, L., \& Barth, M. (2018). Sustainability competencies in teacher education: Making teacher education count in everyday school practice. Journal of Cleaner Production, 174, 821-826. doi: 10.1016/j.jclepro.2017.10.263

Burmeister, M., \& Eilks, I. (2012). An example of learning about plastics and their evaluation as a contribution to education for sustainable development in secondary school chemistry teaching. Chem. Educ. Res. Pract, 13(2), 93-102. doi: 10.1039/ c1rp90067f

Bussey, M. (2008). Embodied education: Reflections on sustainable education. The International Journal of Environmental, Cultural, Economic, and Social Sustainability: Annual Review, 4(3), 139-148. doi: 10.18848/1832-2077/cgp/v04i03/54486 
Cebrián, G., \& Junyent, M. (2015). Competencies in education for sustainable development: Exploring the student teachers' views. Sustainability, 7(3), 2768-2786. doi: $10.3390 /$ su7032768

Chhokar, K. B. (2010). Higher education and curriculum innovation for sustainable development in India. International Journal of Sustainability in Higher Education, 11(2), 141-152. doi: 10.1108/14676371011031865

Darwish, M. M., Agnello, M. F., \& Burgess, R. (2010). Incorporating sustainable development and environmental ethics into construction engineering education. Paper presented at eighth Latin American and Caribbean conference for engineering and technology - Innovation and development for the Americas, Arequipa: Peru. Retrieved from http:/cybertesis.urp.edu.pe/ponencias/LACCEI_2010/Papers/ Papers_pdf/CE168_Darwish.pdf

Davis, S., Edmister, J., Sullivan, K., \& West, C. (2003). Educating sustainable societies for the twenty-first century. International Journal of Sustainability in Higher Education, 4(2), 169-179. doi: 10.1108/14676370310467177

Dawe, G., Gant, R., \& Taylor, R. (2003). Kingston University: Sustainability in the curriculum. Steering Group for sustainability Kingston University.

Dyment, J. E., \& Hill, A. (2015). You mean I have to teach sustainability too? Initial teacher education students' perspectives on the sustainability cross-curriculum priority. Australian Journal of Teacher Education, 40(40). doi: 10.14221/ajte.2014 $\mathrm{v} 40 \mathrm{n} 3.2$

Evans, N., Stevenson, R. B., Lasen, M., Ferreira, J., \& Davis, J. (2017). Approaches to embedding sustainability in teacher education: A synthesis of the literature. Teaching and Teacher Education, 63, 405-417. doi: 10.1016/j.tate.2017.01.013

Gafoor, K. A., \& Mumthas, N. S. (2011, November). Greening teacher education: An analysis of teacher education curricula. Paper presented at UGC sponsored national seminar on Empowering teachers for sustainable development.

Hägglund, S., \& Samuelsson, I. P. (2009). Early childhood education and learning for sustainable development and citizenship. International Journal of Early Childhood, 41(2), 49-63. doi: 10.1007/bf03168878

Hallinger, P., \& Chatpinyakoop, C. (2019). A bibliometric review of research on higher education for sustainable development, 1998-2018. Sustainability, 11(8), 2401. doi: 10.3390/su11082401

Hopkins, C., \& McKeown, R. (2002). Education for sustainable development: An international perspective. In Tilbury, D., Stevenson, R. B., Fien, J., \& Schreuder, D. (Eds.), Education and sustainability: Responding to the global challenge. Gland, Switzerland: IUCN - The World Conservation Union.

Howard, P. (2015). Digital citizenship in the afterschool space: Implications for education for sustainable development. Journal of Teacher Education for Sustainability, 17(1), 23-34. doi: 10.1515/jtes-2015-0002

Ikerd, J. (2014). Deep sustainability; Rediscovering our connectedness. Voices of the Human Spirit, 3(2). Retrieved from https://aboutplacejournal.org/issues/voices/ section-1/john-ikerd/

Iyengar, R., \& Bajaj, M. (2011). After the smoke clears: Toward education for sustainable development in Bhopal, India. Comparative Education Review, 55(3), 424-456. doi: 10.1086/660680 
Kagawa, F. (2007). Dissonance in students' perceptions of sustainable development and sustainability. International Journal of Sustainability in Higher Education, 8(3), 317-338. doi: 10.1108/14676370710817174

Khalil, D., Ramzy, O., \& Mostafa, R. (2013). Perception towards sustainable development concept: Egyptian students’ perspective. Sustainability Accounting, Management and Policy Journal, 4(3), 307-327. Retrieved from https://www.researchgate. net/publication/263567726_Perception_towards_sustainable_development_ concept_Egyptian_students'_perspective

Manni, A., Ottander, C., Sporre, K., \& Parchmann, I. (2013). Perceived learning experiences regarding education for sustainable development - within Swedish outdoor education traditions. Nordic Studies in Science Education, 9(2), 187. doi: 10.5617/ nordina. 653

McKeown, R. (2002). Progress has been made in education for sustainable development. Applied Environmental Education \& Communication, 1(1), 21-23. doi: 10.1080/ 15330150213983

Ministry of Environment, Forest and Climate Change. (n.d.). Climate friendly lifestyles practices in India. Government of India. New Delhi. Retrieved from http://www. moef.gov.in/sites/default/files/Lifestyle\%20Brochure_web_reordered.pdf

Mishra, B. P. (2002). Analysis of the knowledge, attitude and perception regarding sustainable development among pre service and in service teachers at secondary level. Doctoral dissertation, Utkal University Bhubaneswar, Orissa, India.

Mulà, I., Ghazali, M., Tabucanon, M., \& Yasuda, S. (2016). Schooling for education for sustainable development: The contributions of Asia-Pacific regional centres of expertise. In Lambrechts, W., \& Hindson, J. (Eds.), Research and innovation in education for sustainable development. Vienna, Austria: Environment and school Initiatives.

Nolet, V. (2009). Preparing sustainability-literate teachers. Teachers College Record, 111(2), 409-442. Retrieved from http://gcafh.org/edlab/Nolet.pdf

Robinson, J. (2004). Squaring the circle? Some thoughts on the idea of sustainable development. Ecological Economics, 48(4), 369-384. doi: 10.1016/j.ecolecon.2003. 10.017

Salite, I. (2008). Educational action research for sustainability: Constructing a vision for the future in teacher education. Journal of Teacher Education for Sustainability, 10(1), 5-16. doi: 10.2478/v10099-009-0021-6

Sathapathy, M. K. (Ed.). (2010). Education, environment and sustainable development. New Delhi: Shipra Publications.

Steele, F. (2010). Mainstreaming education for sustainability in preservice teacher education: Enablers and constraints. Retrieved from Australian Research Institute in Education for Sustainability website http://aries.mq.edu.au/projects/preservice3/PreService_Teacher_Ed3.pdf

Summers, M., \& Kruger, C. (2003). Teaching sustainable development in primary schools: Theory into practice. Curriculum Journal, 14(2), 157-180. doi: 10.1080/09585170 302836

Şuşnea, I. , Vasiliu, G., \& Spiridon, S. (2014) Beyond the fast food model of education, is the school capable of fostering creativity? Paper presented at the International Conference of Scientific Paper, Barsov, Romania. Retrieved from http://www.afahc. ro/ro/afases/2014/manag/Susnea_vasiliu_spiridon\%20Beyond.pdf 
Tilbury, D. (2007). Monitoring and evaluation during the UN Decade of education for sustainable development. Journal of Education for Sustainable Development, 1(2), 239-254. doi: 10.1177/097340820700100214

Tomas, L., Girgenti, S., \& Jackson, C. (2017). Pre-service teachers' attitudes toward education for sustainability and its relevance to their learning: Implications for pedagogical practice. Environmental Education Research, 23(3), 324-347. doi: 10.1080/13504622.2015.1109065

United Nations Educational, Scientific and Cultural Organization. (2005). Guidelines and recommendations for reorienting teacher education to address sustainability. Retrieved from http://unesdoc.unesco.org/images/0014/ 001433/143370E.pdf

United Nations Educational, Scientific and Cultural Organization. (2006). Education for sustainable development toolkit. Retrieved from https://unesdoc.unesco. org/ ark:/48223/pf0000152453

United Nations Educational, Scientific and Cultural Organization. (2010). Teaching and learning for a sustainable future. Retrieved from http://www.unesco.org/ education/tlsf/mods/theme_gs/mod0a.html

United Nations Educational, Scientific and Cultural Organization. (2018). Integrating education for sustainable development (ESD) in teacher education in South-East Asia. Retrieved from https://bangkok.unesco.org/sites/default/files/2018-10/ 265760E.pdf

Zeegers, Y., \& Clark, I. F. (2014). Students' perceptions of education for sustainable development. International Journal of Sustainability in Higher Education, 15(2), 242-253. doi: 10.1108/ijshe-09-2012-0079

Correspondence concerning this paper should be addressed to Manisha Jetly, Flat Number 204, Block E 9, Society Ghs 79, Sector 20, Panchkula, Haryana - 134116, India. Email: manishaesd@gmail.com 